$10.5935 / 2079-312 X .20170003$

Artículos

\title{
A PROPÓSITO DO USO DE TER E HAVER EM LEXIAS VERBO-NOMINAIS: ANÁLISE CONTRASTIVA PORTUGUÊS-ESPANHOL
}

\section{ON THE USE OF TER (HAVE) AND HAVER (THERE TO BE) IN VERB-PHRASES: CONTRASTIVE ANALYSIS PORTUGUESE-SPANISH}

\author{
Dinah Callou ${ }^{1}$ \\ ${ }^{1}$ UFRJ/CNPq. dcallou@gmail.com
}

\begin{abstract}
Resumo:
Panorama geral de natureza sócio-discursiva de lexias verbo-nominais com os verbos ter/tener e haver/haber, nas chamadas construções com verbos leves, no português brasileiro e no espanhol de Madri e Buenos Aires, com base em dados de língua falada do Projeto NURC$\mathrm{Br}$ e do Macrocorpus da Norma Linguística Culta das Principais Cidades do Mundo Hispânico. A análise comprova a hipótese (i) de existência de diversos graus de funcionalidade do verbo na formação da perífrase em um continuum relacionado à possibilidade de aceitação de determinantes e/ou outros elementos intervenientes entre o verbo e o nome abstrato; (ii) de seu uso ser consequência dos processos de gramaticalização e de lexicalização e (iii) ser necessário considerar restrições de natureza diversa.
\end{abstract}

Palavras-chave: Lexias verbo-nominais; uso variável de ter/tener e haver/haber como verbos leves; gramaticalização; lexicalização

\section{Abstract}


An overview of socio-discursive nature of verb phrases with ter/tener and haver/haber, in the so-called light verbs constructions, in Brazilian Portuguese and European and American Spanish (Madrid and Buenos Aires), based on spoken samples extracted from the NURC-Brazil Project and the Macrocorpus of standard speech of most important cities of the hispanic world. The analyses comfirm the hypotheses of (i) different degrees of functionality of those verbs to the formation of a periphrasis in a continuum, related to the possibility of acceptance of several kinds of intervenient elements between the verb and the abstract noun; (ii) the fact that this use is a consequence of the processes of grammaticalization end lexicalization and (iii) that it is necessary to take in account constraints of different nature.

Key words: Verb-phrases; variable use of ter/tener and haver/haber as light verbs; grammaticalization; lexicalization

Recibido: 05/05/2017

Aceptado: $19 / 05 / 2017$

\section{PANORAMA GERAL}

Os verbos ter e haver, verbos de ampla funcionalidade, já foram objeto de estudo por parte de vários estudiosos, não só do ponto de vista diacrônico, mas também sincrônico, em textos orais e escritos (Almeida 2006; Avelar 2004; Callou e Avelar 2001, 2002, 2013; Mattos e Silva 1996, Viotti 2002, Martins 2005, Duarte et al. 2006, entre outros), com ênfase em construções possessivas, existenciais, modais e na formação de tempos compostos, sob várias perspectivas.

Apesar de não terem sido realizados estudos sistemáticos sobre os estágios por que passou a variação ter/haver, nas estruturas com verbo leve, pode-se levantar a hipótese - a partir das pesquisas feitas por Callou \& Avelar (2000, 2001) e por Portela (1999, 2004), com dados de fala e de anúncios do século XIX, por Eleutério (2002), com textos notariais, do século XVII, por Martins e Almeida (2001), com anúncios de jornais do século XX - de o verbo ter predominar sobre 0 haver, desde o século XVII, principalmente nos casos em que é 
possível a substituição da locução verbo-nominal pelo verbo pleno correspondente.

Neste artigo, nosso foco de interesse é o uso dos verbos ter/tener, haver/haber nas chamadas lexias verbo-nominais, casos denominados ora de verbo leve, ora suporte, ora funcional, predicados complexos que apresentam categoricamente SN complemento abstrato: ter prática, ter motivo, ter coragem, ter falta, ter fama, ter apreço, ter vantagem, ter orgulho, ter privilégio; haver dúvida, haver interrupção.

Essas construções podem ser, em geral, parafraseadas em sentenças similares com um verbo pleno e estão presentes em várias línguas indo-europeias, entre elas, o português, o espanhol, o francês, o inglês, o alemão, com verbos variados, que se repetem, em geral, nas diversas línguas:
(i) Ter, haver, dar, fazer, tomar
(ii) Tener, haber, hacer, dar
(iii) Faire, prendre
(iv) Take, have, make, do
(v) Bringen, kommen

O termo verbo leve ("light verb") foi utilizado por Jespersen (1931), com a observação de que esse tipo de verbo possui um significado geral em si mesmo, mas expressa um significado mais preciso e complexo quando combinado com outra palavra, em geral, um substantivo abstrato. Refere-se ainda o autor ao fato de ser possível acrescentar um elemento interveniente entre os membros da lexia, verbo+nome.

A versatilidade sintática e semântico-discursiva de tais construções aponta para a existência de um continuum que vai desde as construções prototípicas - sem a possibilidade de inserção de um elemento interveniente, o que seria um indício de cristalização dessas perífrases - até as menos prototípicas, que admitem essa inserção, ao que parece, em alguns casos, sem perda do status de verbo 'suporte', embora apresentem o traço [+específico]. A hipótese de existência de diversos graus de funcionalidade do verbo na formação de uma lexia verbo-nominal [+ funcional -$]$, nesse continuum, estaria relacionada à possibilidade de aceitação de determinantes e/ou outros elementos intervenientes entre o verbo e o nome. 
Este uso, como se pode verificar nos exemplos (1) e (2), retirados de textos escritos (anúncios), publicados em jornais brasileiros do século XIX, está presente na história da língua portuguesa, mesmo que nem sempre possa ser enquadrado no que Neves (1996) apresenta como casos prototípicos, estruturas cujo objeto ocorre sem determinante, não havendo, portanto, referencialidade.

(1) o Cevador tem a grande vantagem de ser um remédio poderoso (MG/1860)

(2) a nao Vasco da Gama tem absoluta necessidade de marinheiros (RJ/1850)

Neves (1999) afirma, ainda, que essas construções se situam ora mais próximas de um extremo, ora mais próximas de outro, conforme o grau de gramaticalização a que tenham chegado ou a que tenha chegado o verbo que as integra.

A hipótese de existência de graus de funcionalidade do verbo na formação de uma lexia verbo-nominal estaria, assim, relacionada à possibilidade de aceitação de determinantes e/ou outros elementos intervenientes entre o verbo e o nome e à natureza semântica do termo abstrato. Borba (1996: 79) afirma, em relação à combinação de verbos com nomes abstratos, que certos verbos teriam uma distribuição mais ampla - associam-se a qualquer nome abstrato -, por exemplo, o grupo ter/estar.

Partindo da afirmação de Neves (1996) de o uso de uma lexia verbo-nominal em lugar de um verbo pleno correlato poder corresponder a uma opção do emissor, por necessidade de maior versatilidade sintática, maior adequação/eficácia comunicativa, em suma, por efeitos pragmáticos e maior precisão semântica ou referenciação textual, seria necessário analisar os efeitos de significado dos 'verbos-suporte', a depender da situação comunicativa e intenção do sujeito comunicante, ao fazer a opção por uma ou por outra estrutura.

Para Vieira (2004), os verbos-suporte operam gramaticalmente sobre elementos auxiliados de natureza não-verbal, constituindo assim uma unidade complexa. Desempenham um papel de auxiliar, já que servem como suporte para categorias de tempo, modo, número e 
pessoa e que é o elemento auxiliado não-verbal que define o sentido da estrutura perifrástica. O centro semântico-sintático da sentença desloca-se do verbo para o elemento não-verbal, que pode ser um substantivo ou um adjetivo. Por auxiliaridade, considera-se "a perspectiva de um processo gradual de gramaticalização a que se submetem alguns empregos do verbo" (p.68). Um dado verbo pode ser empregado como verbo predicador, como verbo auxiliar e/ou até mesmo semi-auxiliar.

Portela (2004), analisando construções com os verbos ter, dar e fazer, registra a possibilidade de comutação entre as formas verbais simples - analisar, recear, aconselhar - e perífrases verbo-nominais fazer análise, ter receio, dar conselho. Revela que o verbo ter é o mais produtivo na formação de perífrases e que o grau de formalidade constitui um fator relevante na opção de um verbo pleno ou de uma locução verbo-nominal, uma vez que o número de construções perifrásticas em inquéritos do Projeto NURC-Br do tipo elocução formal (EF) foi bem menor do que em inquéritos do tipo DID (diálogo entre informante e documentador), mais espontâneo.

Em suma, os verbos leves - leves porque semanticamente vazios - são identificados como perífrases (verbo+nome), caracterizadas por uma relação especial entre a sintaxe e a semântica de seus constituintes. Samardzic (2008), sob outro enfoque, em análise de dados do inglês, confirma e esquematiza a diferença entre verbo leve e pleno, do ponto de vista sintático e semântico, mostrando que na construção com verbo leve a sintaxe está no verbo, mas a semântica é dada pelo complemento.

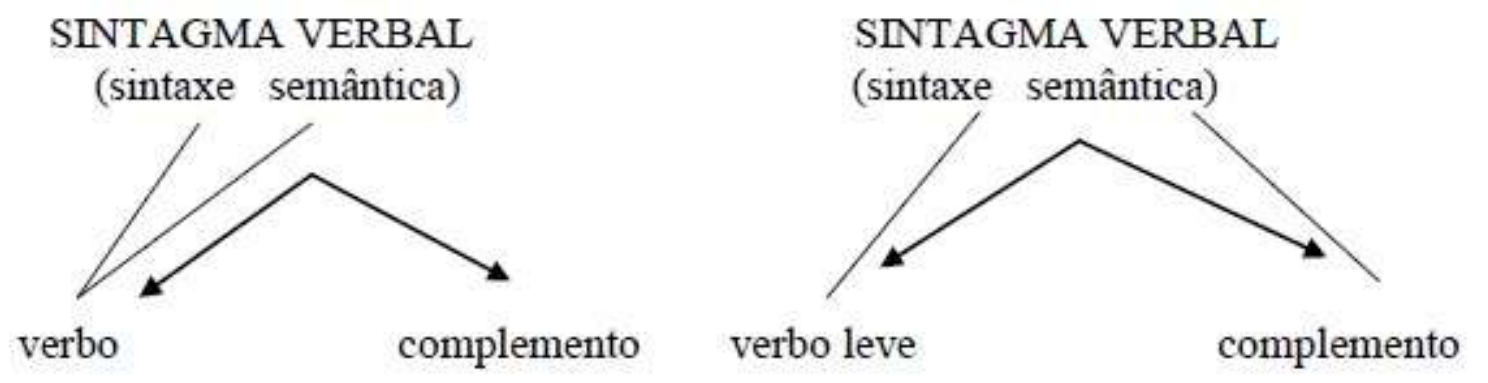

Duarte et al (2006: 326), analisando dados do português europeu, chegam à conclusão, ao contrário de outros autores, de que os verbos leves não são núcleos funcionais nem tampouco auxiliares: "são construções de formação de predicados complexos, i.e., em que 
existe combinações das propriedades léxico-sintácticas de dois predicados lexicais".

Para Pederneira (2014), que analisa o português brasileiro e apresenta uma nova proposta, de cunho forma I - na interface sintaxesemântica - é a configuração sintática que é responsável por diferentes significados.

\section{ANALISANDO AS LEXIAS VERBO-NOMINAIS}

\subsection{Fundamentação teórico-metodológica e corpus}

Tenta-se aliar várias perspectivas teóricas de modo a levantar hipóteses quanto aos condicionamentos linguísticos e extralinguísticos que determinam a opção por parte do emissor por uma estrutura ou outra, e se trabalha na perspectiva da sociolinguística quantitativa laboviana (Labov 1994), a partir da noção de comparabilidade funcional (Lavandera, 1978, 1984), isto é, dois (ou mais) significados distintos das variantes apresentariam uma mesma função/significado abrangente comum.

Na verdade, o objetivo aqui não é mostrar formas alternantes com o 'mesmo valor de verdade', mas sim observar se diferentes construções sintáticas, que guardam entre si uma equivalência no nível referencial, cumprem do ponto de vista discursivo papéis distintos e apresentam as mesmas restrições. Muitas vezes, a opção por uma ou outra construção se deve a um maior ou menor distanciamento do falante em relação ao discurso.

Para confirmar se o uso dos verbos ter e haver em lexias verbonominais está presente também em outras línguas românicas, serão analisadas amostras da chamada fala culta, referentes ao português do Brasil - dados de duas capitais - Rio de Janeiro e Salvador (Projeto 
NURC), gravadas nas décadas de 70 e 90 do século $X X$, e também de língua espanhola, na década de 70, em duas amostras do Macrocorpus da Norma Linguística Culta das Principais Cidades do Mundo Hispânico, com base em falantes de Madri e Buenos Aires, para um possível confronto entre o espanhol peninsular e o americano1[1].

Foram levantadas 128 construções que poderiam ser classificadas como de verbo leve de um total de 1086 construções de ter/haver, para o espanhol (Martins, 2005) - 682 para Madri (MA), 59 como verbo-leve; 404 para Buenos Aires (BA), 69 como verbo leve - e, para o português do Brasil, 665 de um total de 2250 construções de ter/haver.

Tomamos, como ponto de partida, análises variacionistas anteriores sobre textos escritos, numa tentativa de verificar se as mesmas restrições estavam presentes na fala - possibilidade de substituição por verbo pleno e presença de elementos intervenientes e também a relação entre sociolinguística e gramaticalização (Naro e Braga 2000).

Os resultados obtidos a partir de dados de textos escritos do século XX (anúncios de jornal) evidenciam a relação entre a ocorrência de um elemento interveniente e a possibilidade de substituição do verbo leve por um verbo pleno (Figura 1).

1[1] Esses dados foram utilizados por Martins (2005) em sua Dissertação de Mestrado em Língua Portuguesa/ LETRAS/ UFRJ. 


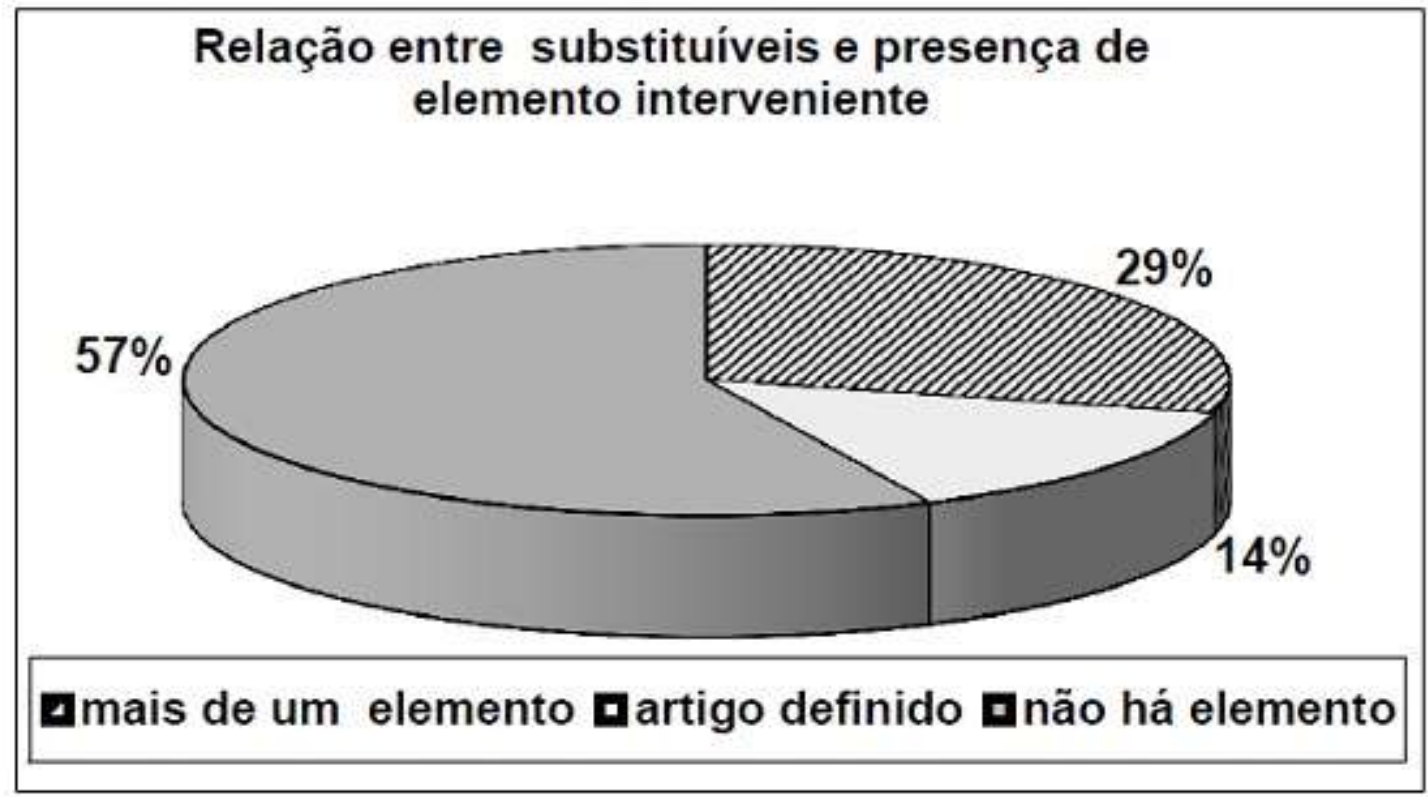

Figura 1: Relação entre 'substituíveis' e presença de elementos intervenientes

em anúncios de jornal, século XX (Martins e Almeida 2001)

De forma complementar, é mais frequente ocorrer a inserção de um ou mais elementos entre o verbo e o nome nos casos em que não há a possibilidade de substituição por um verbo pleno (Figura 2).

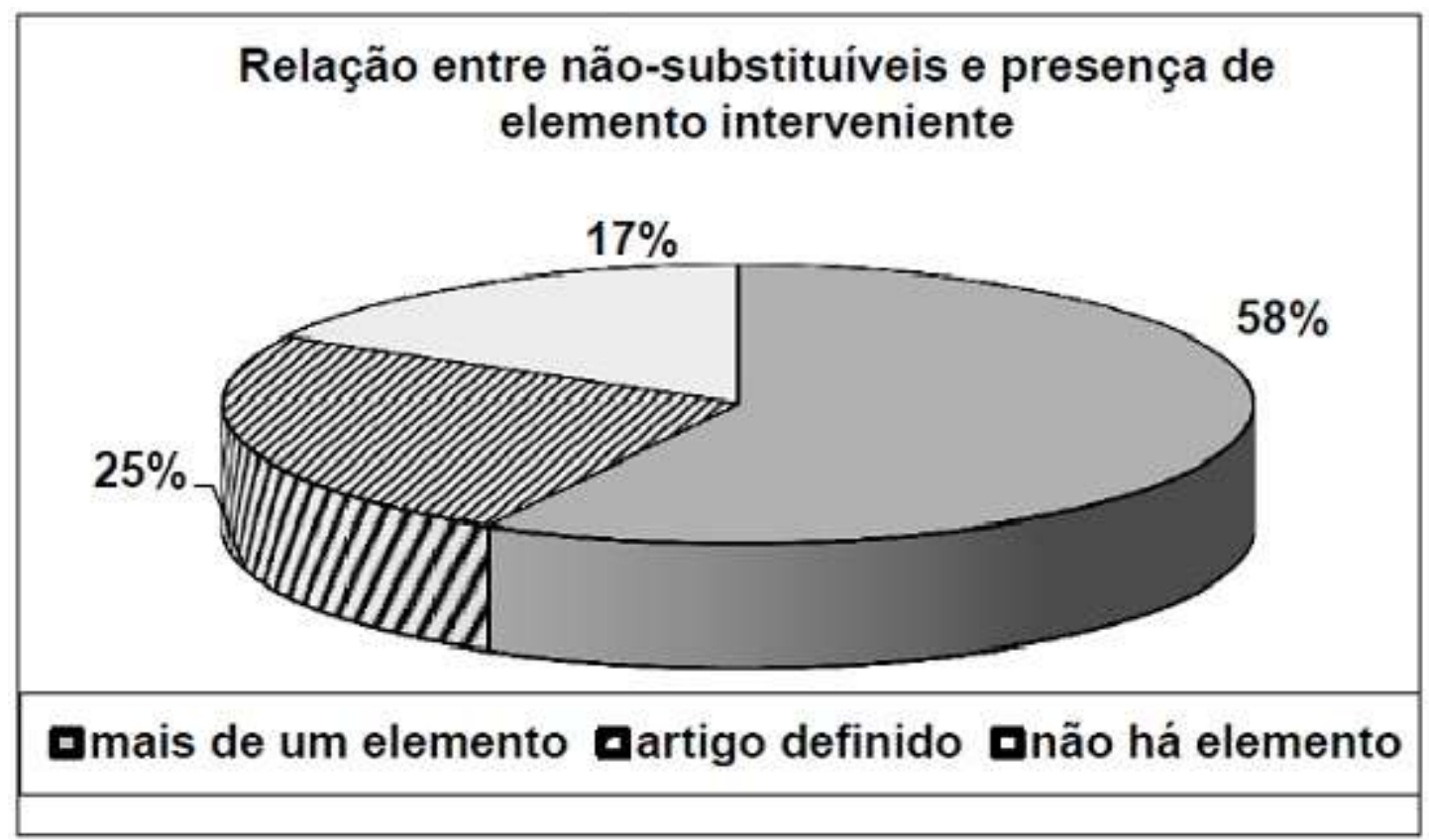

Figura 2: Relação entre 'não-substituíveis' e presença de elementos intervenintes 
em anúncios de jornal, século XX (Martins e Almeida 2001)

\subsection{Uso variável no português brasileiro (Rio de Janeiro e Salvador)}

Os resultados da análise dos dados de fala demonstram a grande produtividade das perífrases verbo-nominais e refletem a tendência, existente em várias línguas, como assinalado anteriormente, ao uso de formas perifrásticas em vez de formas sintéticas (exemplos de 3 a 6).

(3) então havia uma convivência muito grande entre os alunos $(\mathrm{RJ} / 90)$

(4) coitado não teve a delicadeza de levá-la a uma lanchonete (SSA/70)

(5) então nós achamos que temos direito a recebimento integral $(\mathrm{RJ} / 70)$

(6) quer dizer que nós não temos educação para ter animais $(\mathrm{RJ} / 70)$

É possível observar que entre o verbo e o nome, por vezes, ocorrem elementos intervenientes indicadores de frequência (exemplo 7) e demonstrativos que transmitem ao nome uma alta carga de referencialidade (exemplo 8):

(7) também...a...uma...vez por outra a necessidade de um pequeno empréstimo.

(8) nós tínhamos aquela possibilidade de ter os professores que se dedicavam muito mais do que hoje.

Há nomes abstratos com uma ligação tão estreita com o verbo que admitem vários tipos de elementos intervenientes sem perda de sua prototipicidade, podendo ocorrer ainda uma anteposição do nome predicante sem que haja perda do status de verbo-suporte: 
(9) não tenho bem certeza disso não ( $R J / 70)$

(10) eu tenho a impressão que era bujão de gás ( $R J / 70)$

(11) meus irmãos tiveram muito mais liberdade para esse tipo de coisa (SSA/90)

(12) Não aprecio o amor que os homens têm ao futebol $(\mathrm{RJ} / 70)$

(13) ajuda não se tinha nenhuma, muito pelo contrário (SSA/90)

Há casos em que é possível comutar as lexias formadas pelo verbo funcional e o nome abstrato por um verbo pleno:

(14) e nós tínhamos orgulho daquilo porque tudo foi plantado por nós mesmos (RJ/70)

(14 ) e nós nos orgulhávamos daquilo porque tudo foi plantado por nós mesmos

(15) desde que dentro da sala de aula o estudante saiba ter o respeito e o professor também se respeitar (SSA/70)

$\left(15^{`}\right)$ desde que dentro da sala de aula o estudante saiba respeitar e o professor também se respeitar

(16) teatro baiano mesmo a gente não tem costume de ir (SSA/90)

$\left(16^{\prime}\right)$ teatro baiano mesmo a gente não costuma ir

Dentre as ocorrências de verbo-suporte/leve, encontramse lexias que se restringem quase que exclusivamente à oralidade:

(17) hoje em dia eu não tenho saco pra esse tipo de leitura não (SSA/90)

(18) eu não tenho mais saco pra carnaval de clube (SSA/90)

(19) tenho loucura pra conhecer o conservatório (RJ/90)

A possibilidade de substituição por verbo pleno é baixa, tendo inclusive decrescido de uma década para outra no Rio de Janeiro, como mostra a Tabela 1 , a seguir. 


\begin{tabular}{|l|c|c|}
\hline \multirow{2}{*}{$D E ́ C A D A$} & \multicolumn{2}{|c|}{ TER e HAVER } \\
\cline { 2 - 3 } & $\begin{array}{c}\text { NÃO- } \\
\text { SUBSTITUÍVEIS }\end{array}$ & SUBSTITUÍVEIS \\
\hline $\mathrm{RJ} / 70$ & $76 \%$ & $24 \%$ \\
\hline $\mathrm{RJ} / 90$ & $80 \%$ & $20 \%$ \\
\hline $\mathrm{SSA} / 70$ & $67 \%$ & $33 \%$ \\
\hline $\mathrm{SSA} / 90$ & $64 \%$ & $36 \%$ \\
\hline
\end{tabular}

Tabela 1: Distribuição de ter e haver na fala culta por década (adaptado de Martins e Almeida 2001)

Pode-se observar que os casos que admitem essa hipótese são diferenciados, alguns são prototípicos (exemplo 20) e, outros, não prototípicos (exemplo 21):

(20) não tenho costume de comprar esse tipo de revista (SSA/90)

(20 ) não costumo comprar esse tipo de revista

(21) mas o motor que tem a responsabilidade de puxar a água (SSA/90)

(21') mas o motor é que se responsabiliza por puxar a água

No Rio de Janeiro, na década de 90 , o percentual de lexias "substituíveis" que não apresentam elemento interveniente é muito maior - passa de $28 \%$ para $44 \%$-, como se pode verificar na Figura 3, o que sinaliza uma mudança em tempo real de curta duração, nos termos de Labov (1994). Em relação aos elementos intervenientes, não há praticamente alteração.

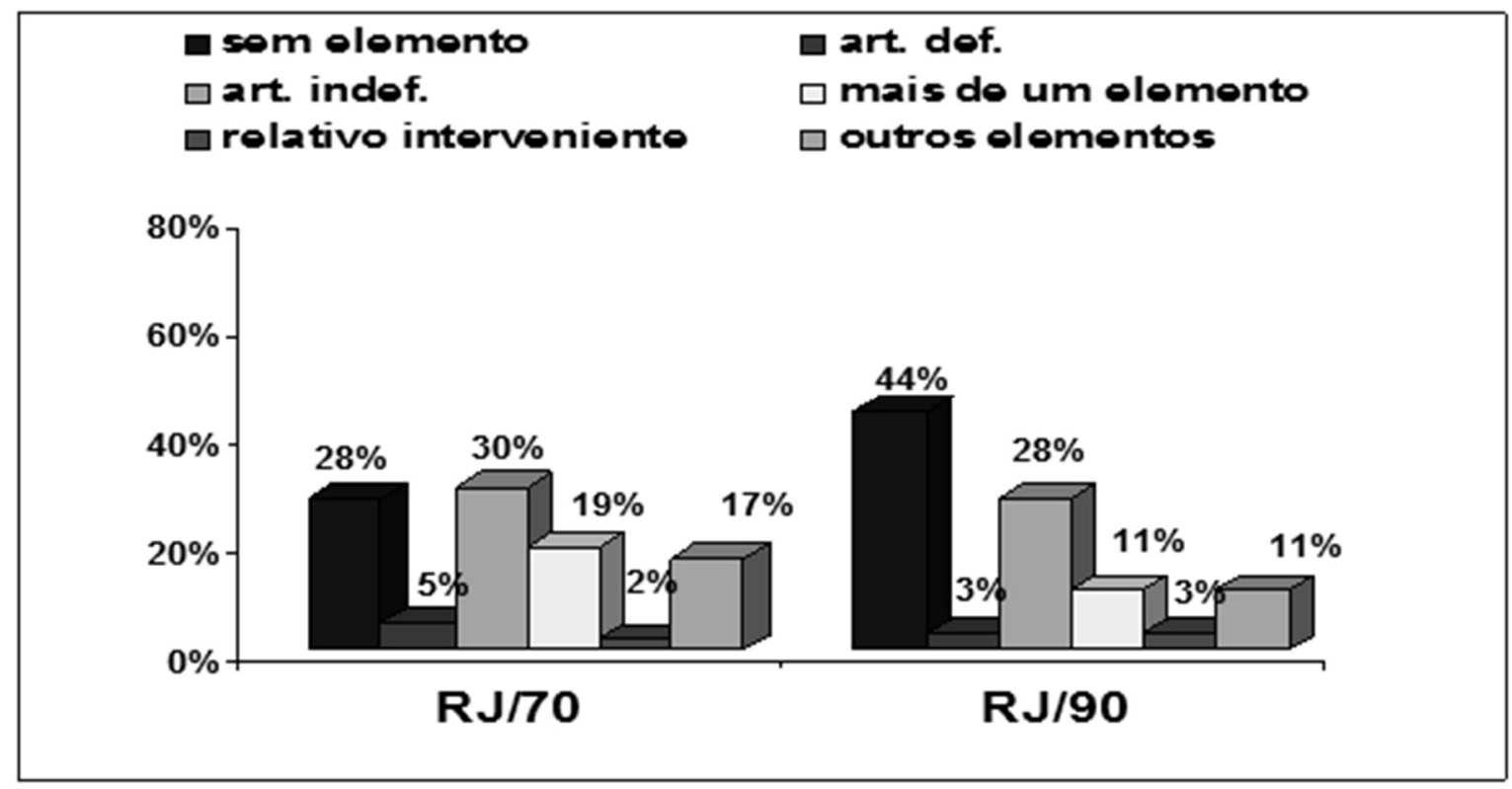


Figura 3: Distribuição das lexias na fala culta por década (adaptado de Martins e Almeida 2001)

\section{A explicação para isso poderia estar na maior integração entre nome e verbo, no sentido da cristalização da lexia verbo- nominal.}

Quanto aos nomes abstratos que integram as lexias, verifica-se que os verbos ter (mais recorrente) e haver se combinam, no corpus de língua falada, aos mais variados termos abstratos:

\section{(i) Com TER:}

TER aceitação; TER afinidade; TER ajuda; TER amadurecimento; TER amizade; TER amor; TER angústia; TER ânimo; TER aparência; TER apoio; TER aptidão; TER assistência; TER atrativo; TER autoconfiança; TER autoridade; TER base; TER capacidade; TER certeza; TER chance; TER classe; TER compensação; TER compreensão; TER compromisso; TER condição; TER condicionamento; TER confiança; TER conforto; TER conhecimento; TER consideração; TER contato; TER convênio; TER convivência; TER coragem; TER cuidado; TER culpa; TER curiosidade; TER deficiência; TER delicadeza; TER destaque; TER desvantagem; TER diferença; TER dificuldade; TER direito; TER disposição; TER divergênia; TER dúvida; TER empecilho; TER esperança; TER exigência; TER experiência; TER facilidade; TER falta; TER fé; TER finalidade; TER função; TER habilidade; TER hábito; TER hora; TER horário; TER horror; TER idéia; TER importância; TER impressão; TER intenção; TER interesse; TER intimidade; TER juízo; TER liberdade; TER medo; TER motivo; TER necessidade; TER noção; TER nojo; TER notícia; TER obrigação; TER opinião; TER oportunidade; TER orientação; TER paciência; TER pavor; TER pena; TER percepção; TER possibilidade; TER prática; TER prazer; TER predileção; TER preferência; TER premência; TER preocupação; TER privilégio; TER problema; TER queixa; TER raiva; TER receio; TER recomendação; TER respeito; TER responsabilidade; TER saudade; TER significação; TER simpatia; TER sorte; TER status; TER surpresa; TER tempo; TER tendência; TER trabalho; TER vantagem; TER vínculo; TER vivência; TER vocação; TER vontade. 
HAVER abuso; HAVER aconchego; HAVER acordo; HAVER alteração; HAVER atenção; HAVER condição; HAVER confusão; HAVER conveniência; HAVER convênio; HAVER convivência; HAVER costume; HAVER cuidado; HAVER desacordo; HAVER desconsideração; HAVER diferença; HAVER diferenciação; HAVER distinção; HAVER divulgação; HAVER dúvida; HAVER equilíbrio; HAVER exagero; HAVER explicação; HAVER falta; HAVER liberdade; HAVER motivo; HAVER multa; HAVER necessidade; HAVER orientação; HAVER participação; HAVER perspectiva; HAVER preocupação; HAVER preparação; HAVER problema; HAVER progresso; HAVER proibição; HAVER punição; HAVER respeito; HAVER restrição; HAVER saturação; HAVER solução; HAVER tempo; HAVER tranqüilidade; HAVER variação.

A variedade de nomes abstratos com os quais esses verbos se combinam confirma o fato de que ter e haver estão entre os verbos-leves mais produtivos, admitindo, sem grandes restrições, uma combinação versátil com vários nomes abstratos.

Neves (1999) afirma que a construção com verbo-suporte é simplesmente mais usual do que a correspondente com verbo simples e que, portanto, é mais conforme à fala coloquial. 0 contexto informal das entrevistas favoreceria $o$ uso dessas construções, já que o indivíduo busca utilizar estruturas de maior valor comunicativo e "menos eruditas" durante $o$ ato de fala.

Portela (1999), ao analisar dados com o verbo dar, atenta para o fato de a presença do determinante ser facultativa, não acarretando mudança de sentido, na maioria das vezes. Entretanto, admite que, em determinados contextos, a omissão ou a permuta de um determinante (artigo definido e indefinido), por outro, possa vir a acarretar mudança de sentido, o nome passando de abstrato a concreto (dar conta versus dar a conta).

A inserção de um artigo definido entre o verbo leve e o nome, algumas vezes, pode tornar a frase agramatical.

(22) tenho pena hoje de quem se propõe a edificar uma casa. 
$\left(22^{\prime}\right) *$ tenho a pena hoje de quem se propõe a edificar uma casa

Vale observar, também, que há lexias que até permitem elementos intervenientes, como em (23), mas perdem a possibilidade de serem substituídas por um verbo pleno, como em (24), porém há nomes abstratos com uma ligação tão estreita com o verbo que admitem vários tipos de elementos intervenientes sem perda de sua prototipicidade, como em (25).

(23) Maria acha que tem a resposta [*responde] para os males do mundo.

(24) A QUALCOMM tem respostas [responde] a estas e outras perguntas inteligentes (RJ/1998)

(25) Antes que você tenha qualquer outra dúvida... (RJ/1998)

A versatilidade dessas construções não é meramente sintática, mas também semântico-discursiva e essa 'variação' sintática não diz respeito apenas ao uso de um verbo leve em lugar de um pleno, se refere também ao elemento que acompanha o nome abstrato e a sua posição dentro da lexia verbo-nominal.

Um dos parâmetros utilizados para classificar essas construções é a sua possibilidade de poderem ser gramaticalizadas ou lexicalizadas. No que concerne ao status de verbo-suporte de alguns itens lexicais verbais, discute-se se estamos diante de um fenômeno de lexicalização ou de gramaticalização. A hipótese é a de que, num primeiro momento, haveria um processo de gramaticalização, com o esvaziamento semântico do verbo - através de sua utilização como verbo auxiliar - e, posteriormente, haveria um processo de lexicalização, com um verbo esvaziado servindo apenas como suporte das categorias gramaticais de modo, tempo, número e pessoa, cabendo ao nome o papel de predicador da sentença:

gramaticalização do verbo e lexicalização da estrutura VERBO + NOME ABSTRATO. O conjunto formado pelo verbo semanticamente esvaziado e o nome predicativo constituiria, portanto, um caso de lexia complexa/predicado complexo. Algumas combinações já se encontram lexicalizadas, pelo menos a partir do século XIX, como em (26) e (27), retirados de anúncios de jornal do século XIX. 
(26) o funeral do mesmo, que teve Iugar no dia 10 do corrente $(P R / 1854)$

(27) "a mesa promotora desta imponente festa tem a honra de convidar as exmas. Devotas e devotos da Elcelsa e Purissima Virgem (BA/1886)

Neves (1996) faz referência ao fato de o uso de uma lexia verbonominal em lugar de um verbo pleno correlato poder corresponder a uma opção do emissor, por necessidade de maior versatilidade sintática, maior adequação/eficácia comunicativa, em suma, por efeitos pragmáticos e maior precisão semântica ou referenciação textual.

No caso de anúncios veiculados em jornais e que possuem um forte apelo comercial, a maior adequação/eficácia comunicativa é um fator essencial para que se atinja o objetivo pretendido pelo anunciante. Uma maior versatilidade sintática que permita a adjetivação e/ou determinação do nome predicante também representa fator relevante na escolha de uma determinada forma linguística para a confecção de um anúncio de objetivo comercial, pois possibilita maior especificação, detalhamento e qualificação de um produto ou serviço.

Com isso, pode-se concluir que a opção pela utilização de uma estrutura com verbo-suporte, que propicia uma comunicação mais eficaz e versátil, em vez da utilização de uma estrutura com um verbo pleno (cognato ou não), constitui um recurso mais próprio - e 'útil' desse tipo de texto. Fica a indagação de as combinações que se encaixam nos casos prototípicos de verbo leve/suporte caminharem no sentido da cristalização de uma lexia verbo-nominal. Saliente-se que algumas perífrases estariam em um estágio mais avançado de lexicalização, isto é, constituírem construções cristalizadas. Num continuum, seriam as que ocupariam o extremo da escala. No outro extremo, estariam construções, possessivas ou existenciais, com VERBO PLENO + NOME ABSTRATO, com verbos que ainda preservam o seu conteúdo semântico.

\begin{tabular}{|c|c|c|}
\hline VERBO PLENO & VERBO-SUPORTE & \\
& $\overrightarrow{\nu_{+}}$ & $\begin{array}{c}\text { EXPRESSÕES } \\
\text { CRISTALIZADAS }\end{array}$ \\
\hline
\end{tabular}




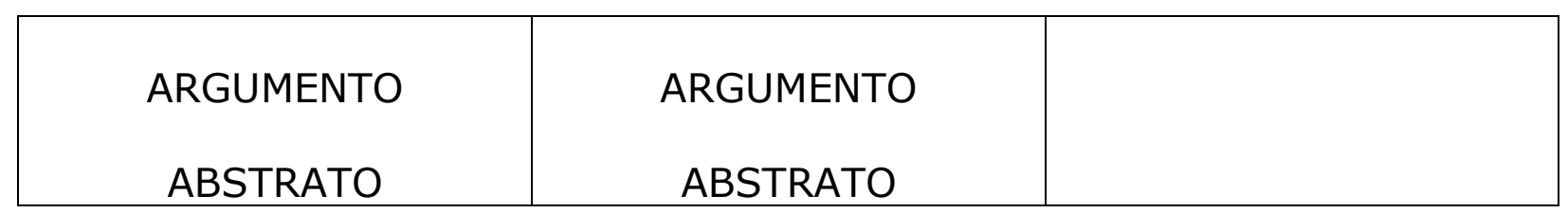

Quadro 1: Proposta de continuum para as lexias verbo-nominais no PB

Acredita-se que as perífrases que se encontram num estágio mais avançado de lexicalização apresentariam uma certa restrição quanto à presença de elementos intervenientes e quanto à inversão da ordem dos constituintes da construção, mais usual na escrita dos séculos anteriores, como nos exemplos (28) e (29), retirados de textos notariais do século XVII.

(28) quem duuida ou embargos tiuesse (XVII)

(29) e pella outra banda com chaos de quem seu direito tiuer nelles (XVII)

Nos corpora analisados foram encontrados poucos exemplos de expressões cristalizadas com ter e haver. Postula-se que as expressões cristalizadas - caracterizadas por se encontrarem num avançado estágio de lexicalização - possuem uma maior fixidez da ordem de seus constituintes, com uma baixa ocorrência de elementos intervenientes.

\subsection{Uso variável no espanhol de Madri e Buenos Aires}

No que se refere ao espanhol, como comentado anteriormente, analisaram-se 128 expressões com tener e haber que poderiam ser classificadas como leve/suporte. Os resultados revelam que, à semelhança do $\mathrm{PB}$, predominam também os casos com tener, pelo menos, na fala culta das variedades analisadas. No caso do português brasileiro, podemos afirmar que tais resultados refletem um dos processos mais característicos da história do português: a substituição 
de haver por ter, iniciada em construções possessivas, estendendo-se aos casos em que os verbos atuam como auxiliares e, por último, aos casos em que atuam como existenciais. Postula-se que o verbo haver, no $P B$, só passe a integrar o inventário linguístico ativo do falante a partir de um processo de escolarização, isto é, que as crianças só o adquiram na escola.

E são justamente os casos em que haver, nas construções existenciais, aparece acompanhado de um argumento interno de caráter [+ abstrato] - podendo ou não ser analisado como verbosuporte - que configuram os contextos de resistência desse verbo. As estruturas com verbo-suporte no espanhol falado culto apresentam comportamento semelhante ao encontrado no português brasileiro.

(30) acepté... este trabajo porque tenía la posibilidad de aprender bastante $y$, por otra parte, económicamente me convenía. (BA-1)

(31) Y además tienen oportunidad de encontrarse todos y conversar, cambiar ideas (BA-5)

Há construções que apresentam elementos intervenientes entre o verbo e o nome abstrato, aparentemente, sem perda do status de verbo-suporte. Ressalte-se que esse julgamento é feito por falante não-nativo, sempre sujeito a discussão.

(32) la mujer tiene doble responsabilidad (BA-8)

(33) y la mujer... el ama de casa, hoy... en día vive duro, vive duro y vive difícil y no tiene mayores estímulos ni mayores alicientes (BA-8)

(34) En fin, un trabajo que no tenía ninguna originalidad, sino que era una recopil... era recopilación más o menos hecha con más o menos felicidad (BA-11)

(35) yo tenía muchas ganas de volver a Madrid (MA-3)

(36) pero vamos, la categoría de la vestimenta, pues no... no había grandes diferencias. (MA-5)

A variedade de elementos intervenientes - adjetivos, pronomes, advérbios, artigos definidos, artigos indefinidos, numerais - comprova a versatilidade sintático-discursiva dessas estruturas perifrásticas. Assim como ocorre no português brasileiro, comprova-se também, na 
fala culta espanhola, que é mais comum a presença de elementos intervenientes quando a lexia verbo-nominal não é comutável por um verbo pleno correspondente.

(37) hay uno que tiene la suerte de... de ser el que pone la última piedra y se lleva la gloria (BA-5)

(38) Y además tienen oportunidad de encontrarse todos y conversar, cambiar ideas (BA-5)

Do total de construções com verbos-suporte, apenas $22 \%$, em Madri, e $16 \%$, em Buenos Aires, são substituíveis, uma diferença não-significativa entre a fala madrilhena e a portenha (Figura 4 ). As construções de (39) a (42) poderiam admitir, em princípio, a substituição da lexia por um verbo pleno correlato2[2].

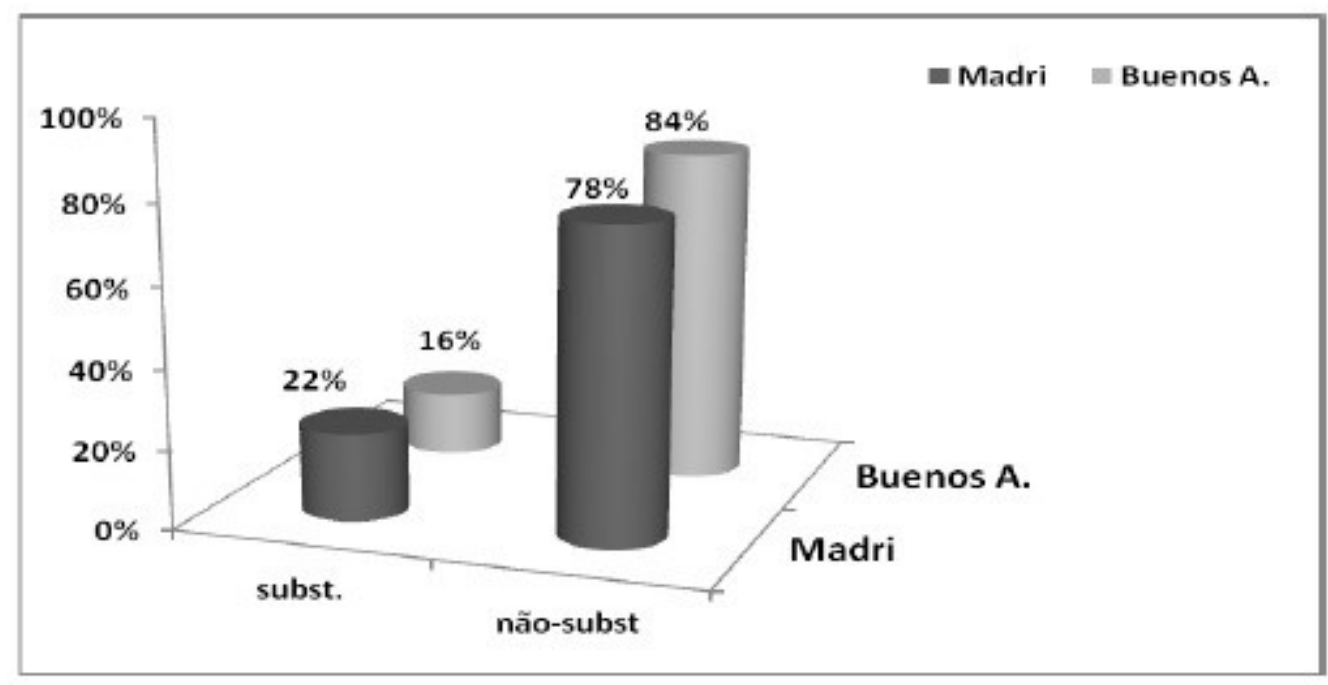

Figura 4: Distribuição das lexias verbo-nominais na fala culta por cidade

(39) Ella tiene terror de viajar en avión (BA-8)

2[2] Para confirmar a hipótese seria necessário aplicar testes de avaliação com falantes nativos nas duas variedades. 
(39') A ella le aterroriza viajar en avión.

(40) mi hijo mayor es grande, porque tiene diecisiete años y es bastante comprensivo y tiene mucha comunicación conmigo (BA-8)

$\left(40^{\prime}\right)$ mi hijo mayor es grande, porque tiene diecisiete años y es bastante comprensivo y se comunica mucho conmigo.

(41) Sí, y por la tarde, no había necesidad de ir con traje de noche a todos sitios (MA-13)

(41') Sí, y por la tarde, no necesitaba ir con traje de noche a todos sitios.

(42) Se puede tener más confianza en ellas, en su... en su vida y en todo. Ahora, la manera de hablar no me gusta nada en absoluto. (MA-13)

(42') Se puede confiar más en ellas, en su...en su vida y en todo. Ahora, la manera de hablar no me gusta nada en absoluto.

Considerando o universo de lexias não-substituíveis na fala culta de Madri, vê-se que há um salto percentual no que diz respeito às construções em que não há elementos intervenientes, o que revela um comportamento distinto do espanhol em relação ao português brasileiro. No PB, inversamente, são as perífrases que não admitem substituição por um verbo pleno as que alcançam o maior índice de não-ocorrência de itens lexicais entre o verbo e o nome. Resta por saber a que se deve essa oposição. 


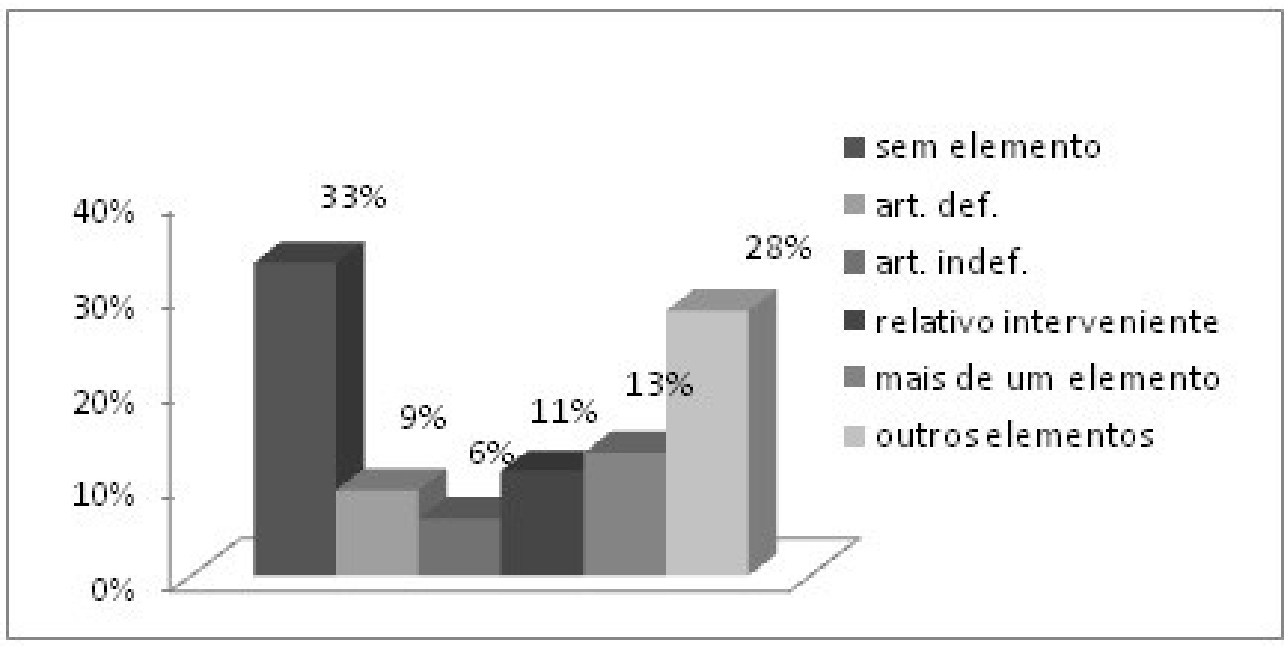

Figura 5: Construções que não admitem substituição em Madri

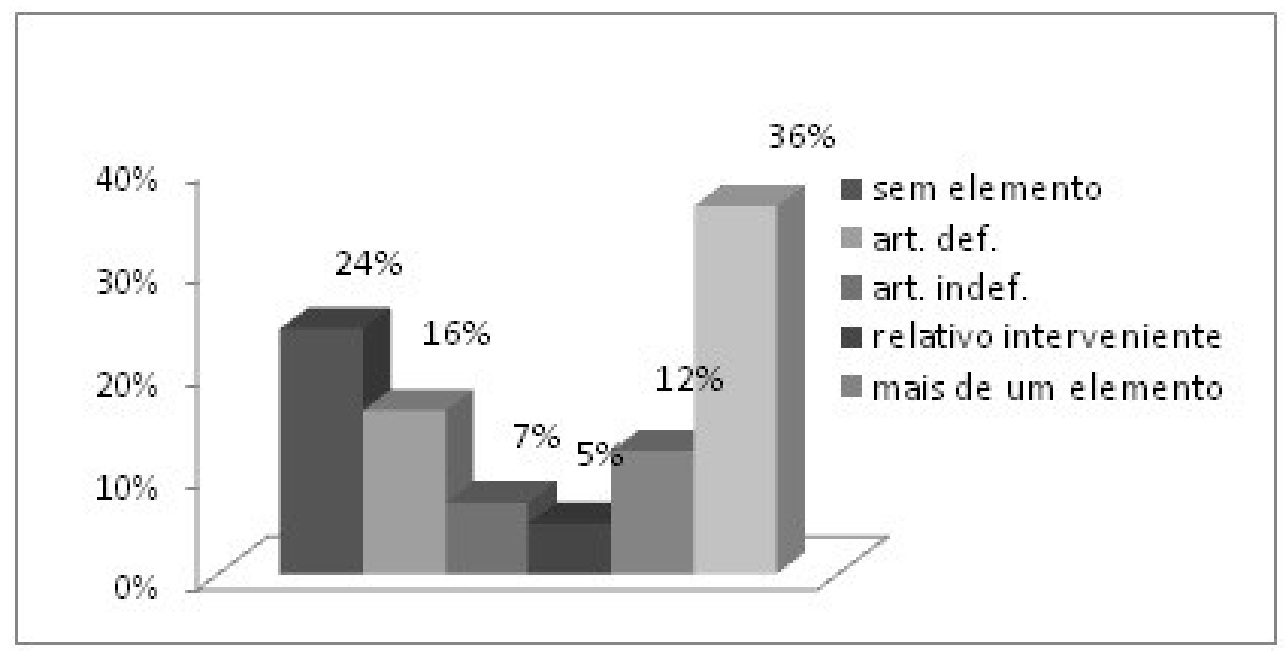

Figura 6: Construções que não admitem substituição em Buenos Aires

Uma listagem com nomes abstratos com os quais os verbos se combinam permite verificar, mais uma vez, a produtividade e versatilidade das construções. No confronto com o PB, percebe-se uma menor variedade de nomes abstratos que integram perífrases verbonominais na fala madrilenha. Tal fato poderia ser atribuído ao menor número de dados nos corpora de língua espanhola considerados neste estudo, talvez por ter sido utilizada apenas a década de 70 do século $\mathrm{XX}$. 


\section{(i) Nomes abstratos anotados na amostra de fala culta de Madri:}

AFICIÓN, AMISTAD, CARÁCTER, COMENTARIO, COMPAÑÍA, COMPETENCIA, COMPLEJO, CONDICIONES, CONFIANZA, CONOCIMIENTO, CONTACTO, CONTACTO, CONTESTACIÓN, CONTROL, COSTUMBRE, CUIDADO, CULPA, DIFERENCIAS, DIFICULTADES, DISCIPLINA, DOTES, EDUCACIÓN, ESTILO, ESTUDIOS, FACILIDAD, FAMA, GANAS, GENIO, IMPORTANCIA, INCLINACIÓN, INCONVENIENTE, INTERÉS, LIBERTAD, MIEDO, NECESIDAD, PERMISO, POTENCIAL, PRESUNCIÓN, PROBLEMA, RAZÓN, RELACIÓN, SATISFACCIÓN, SEGURIDAD, SENTIDO, SUERTE, TIEMPO, TRABAJO.

\section{(ii) Nomes abstratos anotados na amostra de fala culta de Buenos Aires:}

CELO, COMUNICACIÓN, CONCEPTO, CONDICIONES, EMPACHO, ESTÍMULOS, FACILIDAD, IDEA, INCLINACIÓN, INCONVENIENTE, MÉRITO, OBLIGACIÓN, OBLIGATORIEDAD, OPORTUNIDAD, ORIGINALIDAD, PACIENCIA, POSIBILIDAD, PRIVILEGIO, PROBLEMA, RECELO, RECUERDOS, RELACIONES, RESPONSABILIDAD, SENSACIÓN, SUERTE, TERROR, TIEMPO, VERGÜENZA, VOCACIÓN.

De um universo de 139 nomes abstratos registrados no PB e 68 no espanhol peninsular e americano (total de 207) apenas 23 integram as construções perifrásticas, tanto no português brasileiro Rio de Janeiro e Salvador, quanto no espanhol peninsular e americano -- cidades de Madri e Buenos Aires:

(1) AMIZADE/AMISTAD; (2) CONDIÇÃO/CONDICIONES; (3) CONFIANÇA/CONFIANZA; (4) CONHECIMENTO/CONOCIMIENTO; (5) CONTATO/CONTACTO; (6) COSTUME/COSTUMBRE; (7) CUIDADO/CUIDADO; (8) CULPA/CULPA; (9) DIFERENÇA/DIFERENCIAS; (10) DIFICULDADE/DIFICULDADES; (11) FACILIDADE/FACILITAD; (12) IDEIA/IDEA; (13) IMPORTANCIA/IMPORTANCIA; (14) INCLINAÇÃO/INCLINACIÓN; (15) INTERESSE/INTERÉS; (16) INCONVENIENTE/INCONVENIENTE; (17) LIBERDADE/LIBERDAD; (18) MEDO/MIEDO; (19) NECESSIDADE/NECESIDAD; (20) OBRIGAÇÃO/OBLIGACIÓN; (21) SORTE/SUERTE;(22) TEMPO/TIEMPO; (23) VOCAÇÃO/VOCACIÓN. 


\section{CONSIDERAÇÕES FINAIS: RETOMANDO AS INFORMAÇÕES}

O estudo das construções com ter e haver nas quais os verbos atuam como 'verbo-leve/suporte', nas duas línguas, revela que a existência de um continuum de graus de funcionalidade do verbo na formação de uma perífrase verbal parece estar, na maioria das vezes, relacionada à possibilidade de aceitação de determinantes e/ou outros elementos intervenientes entre o verbo e o nome.

A gramaticalização e a lexicalização não são, nos casos dos verbos semanticamente esvaziados que integram lexias verbo-nominais, consideradas como processos que se opõem, ao contrário, justificam a integração entre o item lexical verbal, portador apenas de categorias gramaticais, e, o nome abstrato, predicador da sentença. Os chamados verbos-suporte ou leves funcionariam, assim, para alguns autores de forma semelhante aos verbos considerados auxiliares, como se o item verbal servisse para 'conjugar' o nome predicativo.

A partir das observações de alguns autores, são consideradas construções prototípicas aquelas em que não consta a presença de elementos intervenientes entre o verbo e o nome, embora a presença de elemento interveniente não interfira, muitas vezes, no status de verbo-suporte/leve.

Na verdade, a versatilidade sintática/semântico-discursiva dessas estruturas influenciaria na produtividade e recorrência dessas construções. A possibilidade de inserção de elementos entre o verbo e o argumento interno abstrato condiciona a escolha dessas estruturas pelo enunciador. $\mathrm{O}$ viés variacionista, no entanto, ainda tem muito o que revelar a respeito da alternância entre verbos plenos e perífrases verbais. Trabalhos recentes, de natureza formal, apresentam 
contribuições que poderão trazer um melhor entendimento das relações sintático-semânticas das estruturas com verbos leves.

No confronto entre o português brasileiro e variedades do espanhol, na chamada fala culta, fica evidente que as lexias verbonominais apresentam comportamentos semelhantes.

No que diz respeito ao uso de ter ou haver, constata-se, nos dois idiomas, que ter predomina sobre haver, fato que, no caso do PB, poderia ser explicado pela penetração de ter em todos os campos de atuação do verbo haver, a saber, em estruturas possessivas, existenciais, modais e, ainda, nos casos em que atua como auxiliar.

Por último, postula-se que as expressões cristalizadas constituiriam o estágio mais avançado de lexicalização, processo esquematizado no quadro 2 a seguir.

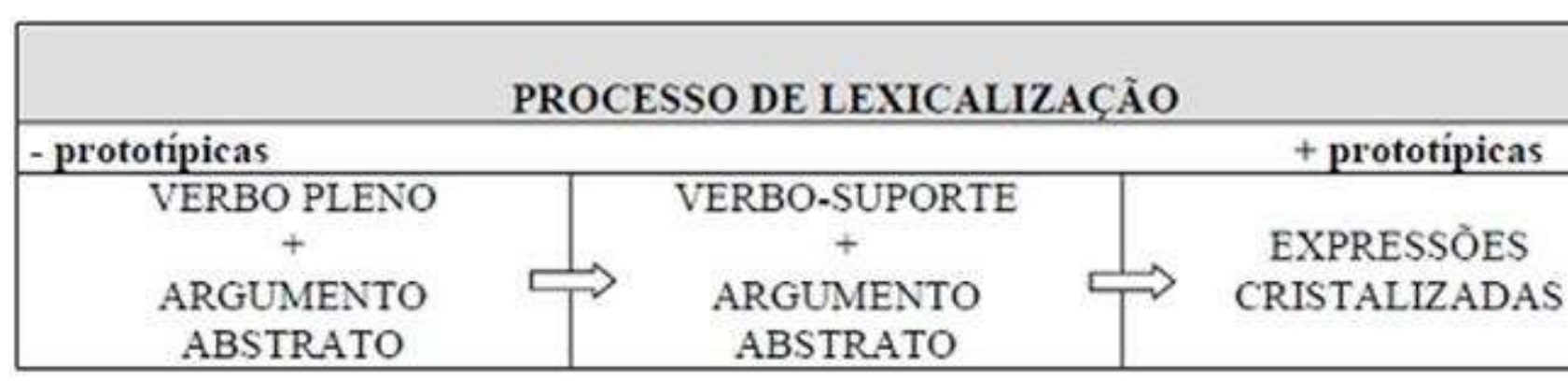

Quadro 2: Proposta de continuum de graus de funcionalidade do verbo na formação da perífrase verbal

\section{REFERÊNCIAS}


Almeida, Erica. 2006. A formação de perífrases verbais no português: um processo diacrônico. Dissertação de Mestrado, Universidade Federal de Rio de Janeiro. [em linea]. Disponivel em http://www.letras.ufrj.br/posverna/mestrado/AlmeidaES.pdf

Avelar, Juanito. 2004. Dinâmicas morfossintáticas com 'Ter', 'Ser' e 'Estar' no Português Brasileiro. Dissertação de Mestrado, Universidade Estadual de Campinas. [em linea]. Disponivel em http://www. bibliotecadigital.unicamp.br/document/?code =vtls00 0343563

Borba, Francisco. 1996. Uma gramática de valências para o português. 1. ed. São Paulo, Ática.

Callou, Dinah e Juanito Avelar. 2000. Ter e haver no português do Brasil. Conferência apresentada no Congresso Internacional sobre os 500 anos de língua portuguesa no Brasil, Universidade de Évora, 8-13 de maio de 2000.

Callou, Dinah e Juanito Avelar. 2001. Sobre ter e haver em construções existenciais: variação e mudança no português do Brasil, Gragoatá, 9: 5-100.

Callou, Dinah e Juanito Avelar. 2002. Estruturas com ter e haver em anúncios do século XIX. Em T. Alkmim (org.), Para a história do português brasileiro. Novos estudos. Vol. III, São Paulo, Humanitas: 47-68.

Callou, Dinah e Juanito Avelar. 2003. 'Ter' and 'haver' in the history of Portuguese: the appearance of 'ter' in existential environments. Trabalho apresentado no NWAVE 32, University of Pennsylvania, outubro 2003.

Callou, Dinah e Juanito Avelar. 2013. Ter/haver-constructions and verbal agrément, Journal of Portuguese Linguistics, 12, 2: 187208.

Duarte, Inês; Anabela Gonçalves e Matilde Miguel. 2006. Verbos leves com nomes deverbais em portugués europeu, em Anais do XXI Encontro Nacional da APL. Lisboa: 315-328.

Eleutério, Sílvia. 2002. A variação ter/haver em documentos notariais do século XVII. Texto para exame de qualificação ao Doutorado, Universidade Federal de Rio de Janeiro. Inédito.

Jespersen, Otto. 1931. A modern English Grammar on historical linguistics, Londres, George Allen \& Unwin.

Labov, William. 1994. Principles of linguistic change. Internal factors. Cambridge, Blackwell.

Lavandera, Beatriz. 1978. Where does the sociolinguistic variable stop?, Language in Society, 7, 2: 171-182.

Lavandera, Beatriz. 1984. Variación y significado, Buenos Aires, Hachette.

Martins, Luciene. 2005. O uso de ter e haver como verbo suporte: um estudo comparativo português/espanhol. Dissertação de Mestrado, Universidade Federal de Rio de Janeiro [em linea]. Disponível em www.letras.ufrj.br pós-graduaçãoVernáculas/teses e dissertações. 
Martins, Luciene e Erica Almeida. 2001. Ter e haver como verbos funcionais. Comunicação apresentada na XXIII Jornada de Iniciação Científica, Universidade Federal de Rio de Janeiro, 6-8 março de 2001.

Mattos e Silva, Rosa Virgínia. 1996. A variação haver/ter, em R. V. Mattos e Silva (org.). A carta de Caminha - Testemunho lingüístico de 1500. Salvador, EDUFBA: 181-193.

Naro, Anthony e Maria Luiza Braga. 2000. A interface sociolinguística/ gramaticalização. Gragoatá, n. 9: 125-134.

Neves, Maria Helena de M. 1996. Estudo das construções com verbosuporte em português, em I. G. V. KOCH. (org.). Gramática do português falado. Vol. VI. São Paulo, UNICAMP.

Neves, Maria Helena de M. 1999. A delimitação das unidades lexicais: o caso das construções com verbo-suporte, Palavra, V: 98-114.

Pederneira, Isabela L. 2014. Verbos leves em português brasileiro: uma nova proposta. Linguística Rio, 1,1: 1-8.

Portela, Kate. 1999. Artigo, definitude e variação: quebrar galho ou quebrar o galho? Revista Interfaces 6: 202-206.

Portela, Kate. 2004. Dar medo; Fazer pesquisa; Ter orgulho: perífrases de uma Dissertação. Dissertação de Mestrado, Universidade Federal de Rio de Janeiro [em linea]. Disponivel em www.letras.ufrj.br pós-graduação-Vernáculas/teses dissertações.

Samardzic, Tanya. 2008. Light verbs and the lexical category bias of their complements. Mémoire de DEA, Université de Genève [em linea]. Disponível em www.unige.ch/lettres/linguistique/samardzic/dea2.pdf

Vieira, Márcia M. 2004. Perífrases verbais: o tratamento da auxiliaridade, em Sílvia Vieira e Sílvia Brandão. (orgs.). Morfossintaxe e ensino de Português: reflexões e propostas. Rio de Janeiro, In-Fólio: 65-96.

Viotti, Evanir. 2002. Sobre o Efeito de Definitude nas Sentenças Existenciais. Revista do GEL, s/n.: 127-153. 